\title{
Drug therapy-related problem management in Nigeria community pharmacy - process evaluation with simulated patient
}

\author{
Showande Johnson Segun * (10) and Lawal Sodiq Damilola
}

\begin{abstract}
Background: Unresolved drug therapy-related problems (DTRPs) have economic and clinical consequences and are common causes of patients' morbidity and mortality. This study evaluated the ability of community pharmacists to identify and resolve DTRPs and assessed the perceived barriers to DTRP identification and resolution.

Methods: A cross-sectional study which employed the use of three simulated patients (SPs) visit to 36 selected community pharmacies in 11 local government areas in Ibadan, Nigeria. The SPs played the role of a patient with prescription for multiple ailments (23-year-old male), type 2 diabetes and hypertensive patient with medication packs (45-year-old male) and hypertensive patient with gastric ulcer with a prescription (37-year-old female). They reenacted three rehearsed vignettes when they spoke with the pharmacists. A five-member panel of experts predetermined the DTRPs present in the vignettes $(n=11)$, actions to take to investigate the DTRPs $(n=9)$ and recommendations to resolve the DTRPs $(n=9)$. Pharmacists' perceived barriers to the identification and resolution of DTRPs were assessed with a self-administered questionnaire. The percentage ability to detect and resolve DTRPs was determined and classified as poor ability ( $\leq 30 \%)$, fair ability (>30 - $\leq 50 \%)$, moderate ability (>50 $-\leq 70 \%)$ and high ability (> 70\%).

Results: One hundred and eight visits were made by the three SPs to the pharmacies. In total, 4.42/11 (40.2\%) DTRPs were identified, 3.50/9 (38.9\%) actions were taken, and 3.94/9 (43.8\%) recommendations were made to resolve the identified DTRPs. The percentage ability of the community pharmacists to detect and resolve DTRPs varied slightly from one vignette to another (vignette 1-49.3\%, vignette 2-39.1\%, vignette 3-38.8\%). But overall, it was fair (40.9\%). Pharmacists' perceived barriers to DTRP detection and resolution included lack of access to patient's/client's medical history and lack of software for DTRP detection.
\end{abstract}

Conclusions: The community pharmacists displayed fair ability in detecting and resolving DTRPs. Several barriers preventing the optimal performance of pharmacist in DTRP identification and resolution were identified including inaccessibility of patient's/client's medical history. The regulatory authority of pharmacy education and practice in Nigeria need to mount Continuing Education Program to address this deficit among community pharmacists.

Keywords: Drug therapy-related problems, Community pharmacy, Pharmacist, Simulated patient, Nigeria

*Correspondence: pharmsegg@yahoo.com; sj.showande@mail1.ui.edu.ng Department of Clinical Pharmacy and Pharmacy Administration, Faculty of Pharmacy, University of Ibadan, Ibadan, Nigeria

\begin{abstract}
Background
Inappropriate drug use, whether over-use or under-use, can cause drug therapy-related problems. Cipolle et al. defined drug therapy problem as any undesirable event experienced by a patient that involves, or is suspected to involve drug therapy, and that interferes with achieving
\end{abstract}


the desired goals of therapy and requires professional judgment to resolve [1]. The occurrence of DTRP may lead to actual or potential clinical consequences [2-4]. As stated by van Mill [3], DTRP can occur when prescribing, dispensing or taking/administering medicines. Unresolved DTRPs may adversely affect the economic, clinical and humanistic outcomes of therapy and also increase morbidity and mortality rate [2]. There has been an increase in the number of hospital admissions resulting from DTRPs. According to a systematic review by Ayalew et al. [5], the prevalence of hospital admission due to DTRPs range from $1.3-43 \%$ and $7 \%$ of hospitalized patients were reported to have died from drugrelated problems.

Besides prescribed drugs, patients also engage in selfmedication which may not be declared to the physicians or is purchased after a hospital visit. Since most drugs for self-medication and prescription refills are obtained from the community pharmacies, community pharmacists are in a vantage position to detect and resolve DTRPs like their hospital counterpart. Pharmacists are concerned with the optimization of patient's pharmacotherapy outcomes by employing pharmaceutical care. The pharmacist's contribution to resolving DTRPs may be evaluated directly by assessing the patient's clinical outcomes or indirectly by assessing the number of DTRPs identified and resolved [6]. The methods used to achieve this include prospective and retrospective reviews of prescriptions, home medicines and case notes [7-10], In another study tools were employed to detect DTRPs [11].

The interventions made by pharmacists in the identification and resolution of DTRPs and their acceptance are sometimes viewed as evidence of clinical significance [6]. Though, this may not be true in all cases as some of the interventions may lack clinical relevance [6]. The methods used in the evaluation of the number of DTRPs detected and resolved across studies vary $[8,12,13]$. To overcome this, some studies employed the use of an independent quality assessment team to evaluate pharmacists activities relating to DTRPs, albeit, retrospectively $[8,12$, 14]. However, drug therapy-related problem identification and resolution are mostly self-reported and sometimes not all the interventions are documented. Thus, the reviewers or the independent quality assessment team are only able to determine the relevance or importance of the self-reported DTRPs [15]. To improve this, we considered using quality assessment team or panel of experts prospectively, that is, to predetermine the number and types of DTRPs identified and other activities of the pharmacists relating to the resolution of DTRPs. This is possible with the use of simulated patients (SPs) otherwise referred to as mystery patient, pseudo-patient, mystery shopper and standardised patient $[16,17]$.
Simulated patients have been used as a methodological tool for objective assessment of pharmacy practices and evaluation of the quality of pharmacists cognitive services [16-21]. These include counselling and education of patients [20], treatment of minor and major ailment [16, 17], and assessment of pharmacists public health services [21]. A SP is a trained individual who enacts a predefined, sometimes scripted, scenario or vignette in a pharmacy to assess a specific pattern of behaviour of the pharmacist or pharmacy staff. Some of the advantages of using SPs are its flexibility, adaptability, standardization, and availability of individuals and possible provision of feedback to the pharmacists [17].

This study, therefore, employed the use of SP model and an independent quality assessment team to evaluate and quantify the ability of community pharmacists to identify and resolve DTRPs presented by simulated patients vis-à-vis identification and investigation of DTRPs and recommendations for resolution. In addition, the study also evaluated the types of DTRPs frequently seen in the pharmacy and the pharmacists' perceived barriers to the identification and resolution of DTRPs.

\section{Methods}

\section{Study design and participant selection}

This cross-sectional study used the SP model and questionnaire survey. The study was conducted in community pharmacies from October 2019 to January 2020 in Ibadan, a metropolitan city in southwest Nigeria and the second-largest city in the country. The city has 11 local government areas (LGAs) comprising of five urban LGAs in the city and six semi-urban LGAs in the town. The local governments are the third tiers of government in Nigeria. At the time of the study, there were $171 \mathrm{com}$ munity pharmacies in the 11 LGAs according to the Pharmacists Council of Nigeria register. Four registered community pharmacies were targeted to be selected from each LGA. The number of community pharmacies in each of the semi-urban LGAs ranged from 1 to 22 while there were 9-24 pharmacies in each of the urban LGA. Two of the semi-urban LGAs namely Ono-Ara and Oluyole LGAs, had one and three registered community pharmacies, respectively. Based on this unequal distribution of community pharmacies in the LGAs, the four community pharmacies in Ono-Ara and Oluyole LGAs were purposively selected because of the low number of pharmacies in these LGAs. Four community pharmacies per LGA were selected from the remaining nine LGAs using computer-generated random numbers. The total number of community pharmacies selected for the study was 40 .

The superintendent pharmacists in the selected community pharmacies were informed of the nature of the study which included a questionnaire guided survey, 
impromptu SP visits, and the recording of the conversation between the pharmacist and the SP, but the identities of the SPs and the time of visits were not revealed to the pharmacists. Consent to conduct the study was sought from each superintendent pharmacist. Forty community pharmacies were planned to be visited. Intern pharmacists and pharmacists on the National Youth Service Corp program (a post-internship mandatory one-year national service programme for fresh graduates) $[16,22]$ were excluded from the study. The lag time, time between the receipt of the last written informed consent from the superintendent pharmacist and the first SP visit to the first pharmacy, was 3 weeks.

\section{Simulated patients}

Three SPs (2 males - 23 and 45 years old, and a 37-yearold female) presented the three vignettes outlined in Table 1 at the community pharmacies. The older male and the female SPs were graduates of Theatre Arts and the younger male SP was an undergraduate final year pharmacy student. Briefly, in vignette 1 , a young male supposedly diagnosed with anaemia, pleurisy, duodenal ulcer, and Tinea pedis presented a prescription to the pharmacist and would like to know if any of the drugs could cause him any harm as he does not like taking drugs. In vignette 2 , a 45-year-old known type 2 diabetes mellitus and hypertensive patient took his medications pack to the pharmacist to help identify if his medications or his diseases were responsible for his weakness. Vignette 3 described a female hypertensive and peptic ulcer patient who had uncontrolled blood pressure due to non-adherence to her hypertensive medications. She took her current prescription to the community pharmacist and sought counsel. The vignettes described in Table 1 were designed by one of the authors, SJS, based on experiences garnered from precepting students on community pharmacy postings. With the assistance of a general practice physician in a private hospital, the pseudo-prescriptions, used for the presentation of vignettes 1 and 3 by the SPs were written solely for the study.

Before the commencement of the study, a 5-member quality assessment panel of experts (made up of three pharmacists in academia from the department of Clinical pharmacy and two community pharmacists) were presented with the three vignettes by the authors. The panel in turn predetermined through a minimum of $80 \%$ consensus: (a) the number and types of DTRPs in the vignettes, (b) actions the pharmacist should take to investigate the identified DTRPs, (c) appropriate recommendations the pharmacist should make. The quality assessment panel of expert used Cipolle et al. [1] classification of DTPs and Epocrates ${ }^{\circledR}$ (a point of care medical application) to select the items above for each vignette. If a drug cause more than one DTRPs, the most important was identified. Also, only drug interactions flagged by Epocrates $^{\circledR}$ as "Serious" or "Use Alternative" were listed as DTRPs. A checklist was prepared based on the panel's consensus (Supplementary Table A1) to assess the ability of the community pharmacists to identify and resolve DTRPs.

Each SP was trained by the authors through 3-5 repeated 2-h mock presentations of the vignettes prior to the re-enactment of the vignettes at the community pharmacies. Table 1 was used as a guide by the SPs on the information to provide to the pharmacist and how to respond appropriately to the pharmacists' questions. The authors acted as pharmacists during the mock presentations and the training continued until the authors were satisfied that the SP presentations were standardized.

Subsequently, each of the three SPs made a separate impromptu visit to each pharmacy at 2 weeks intervals in sequential order. At each pharmacy, the SPs spoke with the salespersons and requested audience with the superintendent pharmacist on duty. Once the pharmacist's attention has been obtained the SP presented either prescription or medication pack to the pharmacist and provided medical and medication history background information when asked. If the pharmacist failed to highlight any potential or actual DTRP, the SP prompted the pharmacist by asking "Is there anything I should be concerned about with this prescription or medications?" Because SPs were used, pharmacists request for clarifications from physicians were directed to one of the authors, SJS, who gave appropriate responses. The conversation between the SPs and the pharmacists was recorded and transcribed verbatim. Studies employing the simulated patient method using audio recording of conversation among community pharmacists had been conducted in the same city [16, 22]. Between 12 and 14 pharmacies were visited per week and the SPs had a week break inbetween to avoid actor's fatigue. The SPs were renumerated after the completion of the visits to the pharmacies.

From the transcripts of the conversation between the pharmacists and the SPs, the two authors independently extracted; (1) the types of DTRPs identified, (2) actions taken to investigate it and (3) the recommendations made to resolve the DTRPs identified using the checklist generated from the expert panel consensus. Differences were resolved through mutual agreement.

\section{Questionnaire}

A self-administered structured questionnaire was given to each pharmacist and retrieved same day by the second author, LSD, after the SPs visits. The questionnaire contained 10 questions on demographic characteristics, a 19-item Likert scale on perceived barriers to DTRP 

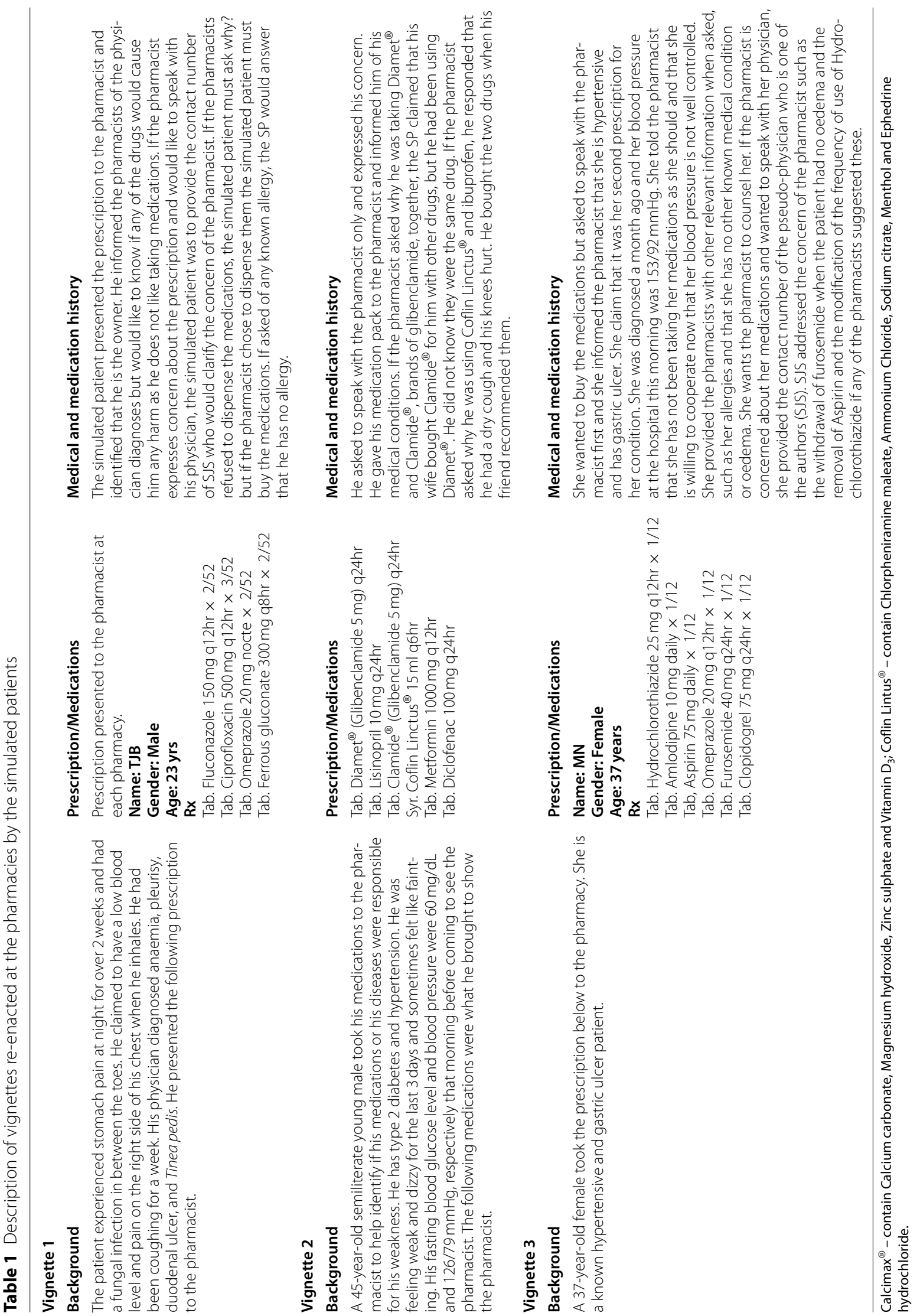
detection and resolution, and another 17-item Likert scale on the types of DTRPs identified and resolved in the pharmacy in the past seven days. An 11-point bipolar scale was employed for each of the two Likert scales. For the 19 -item scale, $0=$ not a barrier; $10=$ very strong barrier while for the 17 -item scale $0=$ Not seen; $10=$ Seen every time. The questionnaire was developed by the authors after literature review [23-25]. The sample questionnaire can be found as Supplementary File A2.

The content and face validity were assessed by four scholars (lecturers in the Department of Clinical Pharmacy who are versatile in the design and use of questionnaire) and through pre-test among 10 non-participating community pharmacists, respectively. For the content validity, all the items considered as extremely relevant by all the scholars were included in the scales used, based on the recommendation of Lynn (1986) [26]. For the pretest, two community pharmacies per LGA were conveniently selected from five urban LGAs. The content validity ensured that the items in the questionnaire addressed the objectives of the study while the face validity ascertained the understanding of the questions by the prospective participants. The questionnaire was retrieved from each participant after completion. The pharmacists were asked after the questionnaire-guided survey if they suspected the visit of any SPs. Two pharmacists suspected a SP visit. One was correct and the other was inaccurate.

\section{Data analysis}

Data were presented as frequencies, percentages, mean \pm standard deviation, and median (interquartile range). Each item on the checklist, mentioned by the pharmacist, was assigned a numerical value of " 1 " and the item not mentioned was scored "0". Mean scores were calculated and converted to percentages. The percentage ability to identify and resolve DTRPs (a composite score from (i) the number of DTRPs identified, (ii) the actions taken to investigate the identified DTRPs, and (iii) the appropriate recommendations made) was calculated as 100(Mean score obtained)/Mean score obtainable, for each vignette. An overall percentage ability to detect and resolve DTRPs was also computed similarly. The percentage ability to detect and resolve DTRPs was further classified through the expert panel consensus as Poor ability $(\leq 30 \%)$, Fair ability $(>30-\leq 50 \%)$, Moderate ability $(>50$ $-\leq 70 \%)$ and High ability (>70\%).

The perceived barriers to DTRP detection and resolution were classified as Weak barrier (Median score, MS: $0-3$ ), Moderately strong barrier (MS: 4-7), and Strong barrier (MS: 8-10). The DTRPs identified and resolved in the pharmacy in the past 7 days were classified as Rarely seen (MS: 0-3), Sometimes seen (MS: 4-7)-, and Often seen (MS: 8-10).
The distribution of the overall scores for percentage ability to detect and resolve DTRPs was tested for normality and homogeneity of variance. Mann-Whitney U tests was used to evaluate the association between gender and the overall percentage ability to detect and resolve DTRPs score. Kruskal-Wallis test on the other hand was used to determine if the distribution of the overall score for percentage ability to detect and resolve DTRPs was the same across the categories of age, year since graduation from pharmacy school, years of community pharmacy experience, and additional qualification. The analysis was performed using the Statistical Package for Social Sciences Windows version 25 (IBM Corp, New York, U.S.A.). Statistical significance was set at $p<0.05$.

\section{Results}

Forty community pharmacists who gave written informed consent were visited but only 36 (90\%) completed the study and were visited by the three SPs. Two of the pharmacists were not on duty after two repeated visits by the first SP (the 23 years old male), while the other two pharmacists were known to the third SP (the 35 years old female). A total number of 108 visits were made to the selected pharmacies by the three SPs. The mean age of the pharmacists was $29.53 \pm 5.20$ years (Table 2), with males being predominant 21 (58.3\%). About $22(61.2 \%)$ of

Table 2 Demographic characteristics of community pharmacists

\begin{tabular}{|c|c|c|}
\hline Demographic characteristics & Mean \pm SD & Frequency (\%) \\
\hline \multicolumn{3}{|l|}{ Gender } \\
\hline Male & & $21(58.3)$ \\
\hline Female & & $15(41.7)$ \\
\hline Age, years & $29.53 \pm 5.20$ & \\
\hline$\leq 27$ & & $14(38.9)$ \\
\hline $28-29$ & & $9(25.0)$ \\
\hline $30+$ & & $13(36.1)$ \\
\hline Year since graduation & $5.12 \pm 2.15$ & \\
\hline$\leq 4$ & & $15(41.7)$ \\
\hline $5-6$ & & $12(33.3)$ \\
\hline $7+$ & & $9(25.0)$ \\
\hline $\begin{array}{l}\text { Years of community pharmacy } \\
\text { practice }\end{array}$ & $3.83 \pm 2.66$ & \\
\hline$\leq 2$ & & $14(38.9)$ \\
\hline $3-4$ & & $11(30.6)$ \\
\hline $5+$ & & $11(30.6)$ \\
\hline \multicolumn{3}{|l|}{ Highest academic qualification } \\
\hline B.Pharm & & $30(83.3)$ \\
\hline PharmD ${ }^{a}$ & & $3(8.3)$ \\
\hline M.Sc. & & $3(8.3)$ \\
\hline
\end{tabular}

B.Pharm Bachelor of Pharmacy is required for pharmacy practice in Nigeria, ${ }^{a}$ PharmD Doctor of Pharmacy is acquired after an intensive 1-year program for B. Pharm degree holders, M. Sc Master of Science. 
the pharmacists had 3 years and above community pharmacy practice experience.

Based on the outcome of the validity assessments of the questionnaire, two questions in the Likert scale were reconstructed. Too much workload was replaced with excess workload, and lack of access to patient's case file was replaced with lack of access to patient/client medical history. More subcategories of DTRPs on adherence were added to the Likert scale evaluating pharmacists encounter with DTRPs in the last 7 days. These included patients cannot afford drug product, directions on the prescription not understood, and patient prefers not to take the prescribed medications. Additional options in a few of the sociodemographic variable were provided, such as the inclusion of Pharm. D as the third option for the variable Highest academic qualification. The questions on years of graduation and practice experience were change to continuous variable (participants were required to fill in the appropriate number of years) instead of categorical variable (range of options for participants to choose from). The Cronbach alpha coefficient for the two scales in the questionnaire was 0.862 and 0.915 .

\section{Vignette 1: 23-year-old SP with prescription for anaemia,} pleurisy, duodenal ulcer, and Tinea pedis

The pharmacists identified 1.58 out of the possible 3 DTRPs on the prescription. Twenty-eight (77.8\%) and $25(69.4 \%)$ pharmacists identified the dose of fluconazole and ciprofloxacin given to the patient as high, respectively. None of the pharmacists checked for drug interactions, but the majority $24(66.7 \%)$ requested to make some clarification from the physician. Most of the pharmacists recommended a reduction in the dose of fluconazole and duration of treatment with ciprofloxacin (Table 3).

\section{Vignette 2: 45-year-old SP who had type 2 diabetes and hypertension}

Most of the pharmacists 31 (86.1\%) were able to detect that the SP was taking a high dose of glibenclamide (two brands of the same product taken together). Thirty-two pharmacists $(88.9 \%)$ suggested the stoppage of one of the glibenclamide brands (Table 4). Likewise, 32 (88.9\%) pharmacists asked the SPs why he was taken the medicines he brought to the pharmacy. Few of the pharmacists, 3 (8.3\%), identified a potential adverse drug reaction with the use of diclofenac and lisinopril together, which may result in reduced renal function.

\section{Vignette 3: 37-year-old SP who was a known hypertensive and gastric ulcer patient}

Unnecessary use of clopidogrel with aspirin and frusemide with hydrochlorothiazide was identified by 25 (69.4\%) and 16 (44.4\%) pharmacists, respectively. Other identified DTRPs in vignette 3 are also listed in Table 5. Thirteen (36.1\%) and 17 (47.2\%) community pharmacists, respectively made some clarification from the SP, and the patients' physician (Table 5). Twenty-six (72.2\%) pharmacists suggested the discontinuation of clopidogrel while a

Table 3 DTRPs identified and resolved by pharmacists in a 23-year-old SP with a prescription

\begin{tabular}{|c|c|c|}
\hline Classification and types of DTRPs & $\begin{array}{l}\text { Identified } \\
\text { n (\%) }\end{array}$ & $\begin{array}{l}\text { Not identified } \\
\mathrm{n}(\%)\end{array}$ \\
\hline \multicolumn{3}{|l|}{ Dosage too high (Prescribed dose too high) } \\
\hline Fluconazole $150 \mathrm{mg}$ instead of $50 \mathrm{mg}$ daily or $150 \mathrm{mg}$ weekly for Tinea pedis & $28(77.8)$ & $8(22.2)$ \\
\hline \multicolumn{3}{|l|}{ Dosage too high (Duration of treatment too long) } \\
\hline $\begin{array}{l}\text { Ciprofloxacin } 500 \mathrm{mg} \text { twice daily for } 3 \text { weeks instead of } 500 \mathrm{mg} \text { twice daily for } 7 \text { - days } \\
\text { for the treatment of pleurisy }\end{array}$ & $25(69.4)$ & $11(30.6)$ \\
\hline \multicolumn{3}{|l|}{ Dosage too low (Drug interaction) } \\
\hline $\begin{array}{l}\text { Omeprazole + ferrous gluconate (omeprazole decreases the level or effect of ferrous } \\
\text { gluconate) }\end{array}$ & $4(11.1)$ & $32(88.9)$ \\
\hline Action taken to investigate DTRPs & $\begin{array}{l}\text { Action taken } \\
\mathrm{n}(\%)\end{array}$ & $\begin{array}{l}\text { Action not taken } \\
\mathrm{n}(\%)\end{array}$ \\
\hline Checked for drug interactions & $0(0.0)$ & $36(100.0)$ \\
\hline Inquire or make clarification from the prescriber & $24(66.7)$ & $12(33.3)$ \\
\hline Recommendations made to resolve the DTRPs & $\begin{array}{l}\text { Recommendation made } \\
\mathrm{n}(\%)\end{array}$ & $\begin{array}{l}\text { Recommendation not made } \\
\mathrm{n}(\%)\end{array}$ \\
\hline $\begin{array}{l}\text { Recommended that prescriber reduce the duration of therapy of ciprofloxacin tablets } \\
\text { for pleurisy to } 7 \text { days. }\end{array}$ & $23(63.9)$ & $13(36.1)$ \\
\hline Recommended the reduction of fluconazole dosage to $50 \mathrm{mg}$ daily. & $22(61.1)$ & $14(38.9)$ \\
\hline
\end{tabular}


Table 4 DTRPs identified and resolved by pharmacists in a 45-year-old type 2 diabetes and hypertensive SP.

\begin{tabular}{|c|c|c|}
\hline Classification and types of DTRPs & $\begin{array}{l}\text { Identified } \\
\mathrm{n}(\%)\end{array}$ & $\begin{array}{l}\text { Not identified } \\
\mathrm{n}(\%)\end{array}$ \\
\hline \multicolumn{3}{|c|}{ Drug therapy is used for an avoidable adverse drug reaction/side effects associated with another medication } \\
\hline Coflin Lintus ${ }^{\circledR}$ possibly for cough associated with lisinopril. & $4(11.1)$ & $32(88.9)$ \\
\hline \multicolumn{3}{|c|}{ Adverse drug reaction ( $A$ drug interaction causes an undesirable reaction that is not dose-related) } \\
\hline Diclofenac + lisinopril decreases renal function ${ }^{\mathrm{a}}$ & $3(8.3)$ & $33(91.7)$ \\
\hline \multicolumn{3}{|l|}{ Dose too high (The dose too high for the patient) } \\
\hline Glibenclamide $10 \mathrm{mg}$ taken twice daily because of duplicate product. & $31(86.1)$ & $5(13.9)$ \\
\hline Action taken to investigate DRP & $\begin{array}{l}\text { Action taken } \\
\mathrm{n}(\%)\end{array}$ & $\begin{array}{l}\text { Action not taken } \\
\mathrm{n}(\%)\end{array}$ \\
\hline Checked for drug interaction. & $2(5.6)$ & $34(94.4)$ \\
\hline Asked for clarification concerning the medicines. & $32(88.9)$ & $4(11.1)$ \\
\hline $\begin{array}{l}\text { Probe the patient further about other symptoms of hypoglycaemia e.g., tremor, } \\
\text { increased heart rate }\end{array}$ & $21(58.3)$ & $15(41.7)$ \\
\hline Recommendations made to resolve the DTRPs & $\begin{array}{l}\text { Recommendation made } \\
\mathrm{n}(\%)\end{array}$ & $\begin{array}{l}\text { Recommendation not made } \\
\mathrm{n}(\%)\end{array}$ \\
\hline Suggested the stoppage of diclofenac tablets. & $6(16.7)$ & $30(83.3)$ \\
\hline Suggested the discontinuation of one of the glibenclamide brand. & $32(88.9)$ & $4(11.1)$ \\
\hline $\begin{array}{l}\text { Suggested the patient see the physician for a possible replacement for lisinopril since } \\
\text { the patient experienced episodes of uncomfortable dry cough. }\end{array}$ & $4(11.1)$ & $32(88.9)$ \\
\hline Suggested the discontinuation of Coflin Lintus ${ }^{\circledR}$. & $3(8.3)$ & $33(91.7)$ \\
\hline
\end{tabular}

DTRPs Drug therapy-related problems, $n$ number of pharmacists, ${ }^{a}$ Serious - Avoid or Use alternative, SP simulated patient.

Coflin Lintus ${ }^{\circledR}$ - contain Chlorpheniramine maleate, Ammonium Chloride, Sodium citrate, Menthol and Ephedrine hydrochloride).

Table 5 DTRPs identified and resolved by pharmacists in a 37-year-old hypertensive SP with gastric ulcer

\begin{tabular}{|c|c|c|}
\hline Classification and types of DTRPs & $\begin{array}{l}\text { Identified } \\
\mathrm{N}(\%)\end{array}$ & $\begin{array}{l}\text { Not identified } \\
\mathrm{N}(\%)\end{array}$ \\
\hline \multicolumn{3}{|c|}{ Unnecessary drug therapy (Multiple drug products were prescribed when single drug therapy is required) } \\
\hline Clopidogrel + aspirin & $25(69.4)$ & $11(30.6)$ \\
\hline Frusemide + hydrochlorothiazide & $16(44.4)$ & $20(55.6)$ \\
\hline \multicolumn{3}{|l|}{ Unnecessary drug therapy (No valid medication indication for drug at this time) } \\
\hline Frusemide is not indicated since there was no oedema. & $15(41.7)$ & $21(58.3)$ \\
\hline \multicolumn{3}{|l|}{ Dosage too low (A drug interaction reduces the amount of drug available) } \\
\hline Omeprazole decreases the level of clopidogrel ${ }^{a}$ & $2(5.6)$ & $34(94.4)$ \\
\hline \multicolumn{3}{|l|}{ Dose too high (The dose too high for the patient) } \\
\hline Hydrochlorothiazide 25 mg twice daily & $6(16.7)$ & $30(83.3)$ \\
\hline Action taken to investigate DTRP & $\begin{array}{l}\text { Action taken } \\
\mathrm{n}(\%)\end{array}$ & $\begin{array}{l}\text { Action not taken } \\
\mathrm{n}(\%)\end{array}$ \\
\hline Checked for drug interactions. & $0(0.0)$ & $36(100.0)$ \\
\hline Asked the simulated patient for clarification on medication-related issues. & $13(36.1)$ & $23(63.9)$ \\
\hline Made clarification from the prescriber on the use of aspirin and clopidogrel together. & $17(47.2)$ & $19(52.8)$ \\
\hline $\begin{array}{l}\text { Made clarification from the prescriber on the concomitant use of Hydrochlorothiazide } \\
\text { and furosemide }\end{array}$ & $17(47.2)$ & $19(52.8)$ \\
\hline Recommendations made to resolve the DTRPs & $\begin{array}{l}\text { Recommendation made } \\
\mathrm{n}(\%)\end{array}$ & $\begin{array}{l}\text { Recommendation not made } \\
\mathrm{n}(\%)\end{array}$ \\
\hline $\begin{array}{l}\text { Suggested to the physician the use of hydrochlorothiazide only instead of hydrochloro- } \\
\text { thiazide and frusemide together. }\end{array}$ & $14(38.9)$ & $22(61.1)$ \\
\hline Suggested the discontinuation of clopidogrel & $26(72.2)$ & $10(27.8)$ \\
\hline Suggested reduction in hydrochlorothiazide $25 \mathrm{mg}$ frequency of use to once daily. & $12(33.3)$ & $24(66.7)$ \\
\hline
\end{tabular}

DTRPs Drug therapy-related problems, ${ }^{2}$ Serious - Avoid or Use alternative, SP simulated patient. 
few 12 (33.3\%) suggested a reduction in the frequency of use of hydrochlorothiazide to once daily.

In total, 4.42/11 (40.2\%) DTRPs were identified, 3.50/9 (38.9\%) actions were taken to investigate the DTRPs, and 3.94/9 (43.8\%) recommendations were made to resolve identified DTRPs (Table 6). The percentage ability of the community pharmacists to detect and resolve DTRPs varied slightly from one vignette to another (vignette $1-49.3 \%$, vignette $2-39.1 \%$, vignette $3-38.8 \%$ ). But overall, the percentage ability of the community pharmacists to detect and resolve DTRP was fair (40.9\%). The most frequently encountered DTRP in the community pharmacies was the problem of adherence where patients could not afford the drugs (Table 7). Part of the strong barriers to the detection and resolution of DTRPs as reported by the community pharmacists were impatience on the part of patients/clients, and lack of access to patient's/client's medical history (Table 8).

A Mann-Whitney $U$ test revealed no significant difference in the overall percentage ability to detect and resolve DTRPs of males (Mean rank $=20.14, n=21$ ) and females (Mean rank $=16.20, n=15$ ), $U=123, p=0.279$.
Kruskal-Wallis test showed no significant differences in the categories of age, year since graduation, and years of community pharmacy practice experience for the overall percentage ability to detect and resolve DTRPs $(p>0.05)$, Table 9. Kruskal Wallis test also revealed a statistically significant difference in the overall percentage ability to detect and resolve DTRPs across the three groups of pharmacists' highest academic qualifications (B.Pharm, $n=30$, Mean rank $=17.25$; Pharm. D, $n=3$, Mean rank=34.83; M.Sc., $n=3$, Mean rank $=14.67)$, $x^{2}$ $(2, n=36)=8.043, p=0.018$, Table 9. Pharmacists with Pharm. D as additional qualification had the highest mean rank.

\section{Discussion}

The community pharmacists in this study displayed a fair ability to detect and resolve DTRPs, vis-à-vis identification of DTRPs, investigation of the causes and recommendations for resolution. The DTRPs mostly identified were dosage too high and unnecessary drug therapy. Others were the need for additional drug therapy and adverse drug reactions. Interestingly, most of the pharmacists did

Table 6 Mean score with the percentage ability to detect and resolve DTRPs

\begin{tabular}{|c|c|c|c|c|}
\hline Description & Mean score \pm S.D & $\begin{array}{l}\text { Maximum score } \\
\text { obtainable }\end{array}$ & $\begin{array}{l}\% \text { Ability to detect and } \\
\text { resolve DTRPs, }(95 \% \mathrm{CI})\end{array}$ & Interpretation \\
\hline \multicolumn{5}{|l|}{ Vignette 1} \\
\hline DTRPs identified & $1.58 \pm 0.97$ & 3 & & \\
\hline Actions taken to investigate DTRPs & $0.67 \pm 0.48$ & 2 & & \\
\hline Recommendations made & $1.25 \pm 0.94$ & 2 & & \\
\hline Composite score & $3.50 \pm 2.26$ & 9 & $49.5(38.5,60.6)$ & Fair \\
\hline \multicolumn{5}{|l|}{ Vignette 2} \\
\hline DTRPs identified & $1.06 \pm 0.48$ & 3 & & \\
\hline Actions taken to investigate DTRPs & $1.53 \pm 0.61$ & 3 & & \\
\hline Recommendations made & $1.25 \pm 0.73$ & 4 & & \\
\hline Composite score & $3.83 \pm 1.18$ & 10 & $39.1(35.2,43.2)$ & Fair \\
\hline \multicolumn{5}{|l|}{ Vignette 3} \\
\hline DTRPs identified & $1.78 \pm 1.46$ & 5 & & \\
\hline Actions taken to investigate DTRPs & $1.31 \pm 1.26$ & 4 & & \\
\hline Recommendations made & $1.44 \pm 1.16$ & 3 & & \\
\hline Composite score & $4.53 \pm 3.54$ & 12 & $38.8(28.6,49.0)$ & Fair \\
\hline Total DTRPs identified & $4.42 \pm 1.90$ & & & \\
\hline Total action taken to investigate the DTRPs & $3.50 \pm 1.61$ & & & \\
\hline Total Recommendations made & $3.94 \pm 1.66$ & & & \\
\hline Overall composite score & $11.86 \pm 4.70$ & 29 & $41.0(35.5,46.4)$ & Fair \\
\hline
\end{tabular}

CI Confidence Interval, S.D Standard Deviation.

$\%$ Ability to detect and resolve DTRPs, (a composite score of the percentage ability to detect DTRPs, investigate it, and make appropriate recommendation) for each vignette and the three vignettes combined:

Poor ability $(\leq 30 \%)$.

Fair ability $(>30-\leq 50 \%)$,

Moderate ability $(>50-\leq 70 \%)$ and.

High ability (>70\%). 
Table 7 Types of DTRPs seen in the pharmacies in the last 7 days by community pharmacists

\begin{tabular}{lll}
\hline DTRP Categories & Drug therapy-related problems & $\begin{array}{c}\text { Description of encounter } \\
\text { Median (IQR) }\end{array}$ \\
\hline & & Encounter sometimes seen \\
Need Additional Therapy & Untreated condition & $6.00(3.25-7.00)$ \\
Unnecessary Drug Therapy & Non-drug therapy should have been recommended & $6.50(4.00-7.00)$ \\
& Duplicate therapy & $6.00(2.00-8.75)$ \\
Ineffective Drug & Dosage form prescribed is inappropriate & $6.50(3.00-9.00)$ \\
& Contraindication present & $5.00(0.25-8.00)$ \\
Dose too Low/Dose too High & Drug prescribed will not be effective for the patient & $5.00(2.00-7.00)$ \\
Dose too Low & Wrong dose prescribed & $7.00(2.00-8.00)$ \\
Adverse Drug Reaction & Frequency of use too long & $7.00(3.00-8.00)$ \\
& Duration of therapy too short & $5.50(1.00-7.00)$ \\
Adherence & Drug interaction present & $6.00(2.00-7.00)$ \\
& Drug prescribed may not be safe for patient & $6.00(4.00-7.00)$ \\
& Possibility of patient experiencing ADR & $5.00(1.00-7.00)$ \\
& Prescribed product not readily available & $6.00(2.50-7.25)$ \\
& Patient cannot tolerate the prescribed dosage form & $4.00(1.25-7.00)$ \\
& Directions on the prescription not understood & $5.00(0.00-8.00)$ \\
Encounter often seen & $8.00(6.25-10.00)$
\end{tabular}

DTRPs Drug therapy-related problems.

Description of DTRP encounters based on Median score:

$0-3:$ Rarely seen,

4-7: Sometimes seen,

8-10: Often seen.

not check for drug interactions. However, a greater number of the pharmacists asked the SPs for further clarifications on medication-related issues and between 47 and $67 \%$ of the pharmacists contacted "the physicians" of the SPs on suspected DTRPs and suggested recommendations on how to resolve identified DTRPs. As high as $89 \%$ of the pharmacists made appropriate recommendations which bordered on dosage adjustment, drug discontinuation, and drug substitution.

The fair ability to detect and resolve DTRPs (41\%) displayed by the community pharmacists differs from two other similar studies where independent quality assessment teams were also used to evaluate pharmacists' DTRP activities. In Ewan and Greene [15] and Gisev et al. [14], the expert review panels deemed 91 and $76 \%$ of the DTRP interventions made by the pharmacists appropriate, respectively. In these two studies, the findings of the pharmacists were retrospectively assessed by experts while the DTRPs in this study was predetermined by the panel of experts and compared with the pharmacist's findings. Interstudy comparison may be difficult as studies use different scoring criteria [6, 11, 27-33], such as the use of an independent assessment team or panel, to assess the quality of pharmacists DTRPs interventions. The composition of such panel, which vary across studies, may impact on the judgment or final evaluation of the performance of the pharmacists, since members of the panel may have different concept of clinical relevance of DTRP interventions $[8,12,14]$. Nevertheless, the ability of community pharmacist in this study to detect and resolve DTRPs was low compared with the two studies. The differences may be due in part to the study settings, study populations, definition of DTRPs, and the methods of identifying the DTRPs $[5,34]$ but mostly as a result of the study design. To the best of our knowledge, this is the first time a SP model along with an independent quality assessment panel of experts who determined the DTRPs and possible resolutions in a given scenario prospectively was used to assess pharmacist's ability to identify and resolve DTRPs. Several other studies used the independent quality assessment panel of experts to determine the quality of identified and resolved DTRPs by pharmacists retrospectively $[8,12,14]$.

The DTRPs, dosage too high and unnecessary drugs, were identified by most of the pharmacists compared with a study in Ethiopia reporting a low level (4\%) of 
Table 8 Community pharmacists' perceived barriers to drug therapy-related problems detection and resolution

\begin{tabular}{|c|c|}
\hline Barriers to DTRP detection and resolution & $\begin{array}{l}\text { Categories of barriers to DRP } \\
\text { Median (IQR) }\end{array}$ \\
\hline \multicolumn{2}{|l|}{ Patient-related barriers } \\
\hline & Strong barriers \\
\hline Impatience on the part of patients/clients & $8.00(5.00-10.00)$ \\
\hline \multirow[t]{2}{*}{ Lack of access to patient/client medical history } & $8.00(6.00-9.00)$ \\
\hline & Moderately strong barriers \\
\hline Patient's level of education & $7.00(6.00-8.00)$ \\
\hline Patient's attitude & $7.00(5.00-8.00)$ \\
\hline \multicolumn{2}{|l|}{ Interprofessional collaboration barriers } \\
\hline Difficulty in contacting the physician & $6.50(4.25-9.00)$ \\
\hline Negative physician attitude towards pharmacist recommendation & $6.50(5.00-9.00)$ \\
\hline \multicolumn{2}{|l|}{ Practice/profession-related barriers } \\
\hline Excessive workload & $6.50(5.00-8.75)$ \\
\hline Lack of adequate training & $6.50(3.25-8.75)$ \\
\hline Lack of time & $5.00(4.00-8.00)$ \\
\hline Inadequate qualified personnel & $6.00(3.00-7.00)$ \\
\hline Lack of remuneration for pharmacist & $5.50(3.25-8.00)$ \\
\hline Lack of documentation skill & $6.00(5.00-8.75)$ \\
\hline Inadequate communication skill with patients & $4.50(2.25-8.00)$ \\
\hline Difficulty in accessing drug information & $5.00(2.25-7.75)$ \\
\hline \multicolumn{2}{|l|}{ Pharmacy-related barriers } \\
\hline Lack of software to make the detection of DTRPs easy & $5.50(5.00-9.00)$ \\
\hline Lack of space & $4.00(0.25-5.75)$ \\
\hline Lack of motivation for pharmacist & $4.50(1.00-8.00)$ \\
\hline Lack of internet facility & $4.50(1.25-6.75)$ \\
\hline Pharmacy layout & $5.00(1.00-6.00)$ \\
\hline
\end{tabular}

DTRPs Drug therapy-related problems, IQR Interquartile range,

Categories of barriers:

Median score 0-3: Weak barrier,

Median score 4-7: Moderately strong barrier,

Median score 8-10: Strong barrier,

identification of the DTRP - dosage too high [7]. In two other related studies conducted in Minnesota, U.S.A and Jos Nigeria, the lowest-rated DTRP was unnecessary drug therapy [32, 35]. But in other studies, DTRPs such as drug interactions, unnecessary drugs therapy, and adverse drug reaction, identified by few community pharmacists in this study, were commonly reported among patients $[7,32,36]$. The reason why few of the pharmacists did not identify some of these frequently reported DTRPs could be because the DTRPs were infrequently seen in the pharmacy (Table 7).

The fair ability displayed by the pharmacists to detect and resolve DTRPs may also be due to some of the perceived barriers mentioned by the pharmacists. These included inadequate training and lack of documentation skill among others. This is corroborated by Williams et al. [37] study which reported a strong correlation between pharmacists clinical knowledge and level of additional training, and the ability of pharmacists to detect, obtain relevant information and proffer resolution for DTRPs. The finding in this study agrees with Williams et al. [37] report because community pharmacists with Pharm. D degree seem to perform better in detecting and resolving DTRPs.

In Nigeria, Pharm. D may be acquired after an intensive one-year clinically oriented program for Bachelor of Pharmacy degree holders [38]. The National University Commission approved the Pharm. D degree program as undergraduate National degree in 2016 $[39,40]$. Currently the Bachelor of Pharmacy degree is the minimum requirement to practise as pharmacist in Nigeria but soon the Pharmacists Council of Nigeria may set the Pharm. D degree as the minimum requirement [41]. Presently 11 Universities have been approved to run the Pharm. D degree programme [42]. 
Table 9 Association between demographic variables and overall percentage ability score to detect and resolve drug therapyrelated problems

\begin{tabular}{|c|c|c|c|}
\hline $\begin{array}{l}\text { Demographic } \\
\text { characteristics }\end{array}$ & $\mathrm{N}$ & Mean rank & $p$-value \\
\hline \multicolumn{4}{|l|}{ Gender } \\
\hline Male & 21 & 20.14 & \multirow[t]{2}{*}{$0.279^{\mathrm{a}}$} \\
\hline Female & 15 & 16.20 & \\
\hline \multicolumn{4}{|l|}{ Age, years } \\
\hline$\leq 27$ & 14 & 19.29 & \multirow{3}{*}{$0.785^{b}$} \\
\hline $28-29$ & 9 & 16.39 & \\
\hline $30+$ & 13 & 19.12 & \\
\hline \multicolumn{4}{|c|}{ Year since graduation } \\
\hline$\leq 4$ & 15 & 15.23 & \multirow{3}{*}{$0.218^{b}$} \\
\hline $5-6$ & 12 & 22.33 & \\
\hline $7+$ & 9 & 18.83 & \\
\hline \multicolumn{4}{|c|}{ Years of community pharmacy practice } \\
\hline$\leq 2$ & 14 & 16.68 & \multirow{3}{*}{$0.697^{b}$} \\
\hline $3-4$ & 11 & 19.23 & \\
\hline $5+$ & 11 & 20.09 & \\
\hline \multicolumn{4}{|c|}{ Highest academic qualification } \\
\hline B.Pharm & 30 & 17.25 & \multirow{3}{*}{$0.018^{* b}$} \\
\hline PharmD & 3 & 34.83 & \\
\hline M.Sc. & 3 & 14.67 & \\
\hline
\end{tabular}

B.Pharm Bachelor of Pharmacy is required for pharmacy practice in Nigeria, PharmD Doctor of Pharmacy.

${ }^{*} P<0.05,{ }^{a}$ Mann Whitney $\mathrm{U}$ test, ${ }^{\text {b }}$ ruskal Wallis test

It should be taken into consideration the diversity of therapeutic areas covered in the vignettes and the number of issues within a prescription that might have impacted the results not under-estimating the need for pharmacists to have identified the DTRPs. Variations in pharmacy staff and pharmacist's behaviour, when presented with different scenarios, have been reported in pharmacy practice [43-47]. Inconsistencies in pharmacist's behaviour between or within vignettes could be a pointer to the underlying process that drives pharmacy practice. Such factors include lack of time, patient's attitude, difficulty in contacting physicians, lack of remuneration or motivation among other perceived barriers to identify and resolve DTRPs as reported here and highlighted in the literature [23-25, 48-50]. The common conclusion when the pharmacist's performance is substandard is the need for additional training. However, this may not automatically improve the quality of performance. Though, the variability in the performance of the community pharmacists reported here may be reflective of deficiencies in tailored clinical training programs. From the foregoing, there is a need for the inclusion of courses on the detection and resolution of DTRPs in Continuing Education Program for pharmacists, especially those in this study, to improve performance. However, these courses should be extended beyond the clinical perspective to include communication skills for effective interaction with patients or pharmacy clients [47]..

The inability of pharmacists to detect and resolve drug interactions may lead to the development of ADRs and subsequent hospitalization. Yet few of the pharmacists were able to spot a significant drug interaction such as the use of omeprazole with Ferrous gluconate. None of the pharmacists used Medscape, Epocrates or any drug interaction textbook. The lack of software for DTRP detection, lack of stable internet facility, and difficulty in accessing drug information were barriers perceived by the community pharmacists that could have limited the pharmacist's ability to investigate suspected DTRPs. Hence the provision of subsidized commercially available medication review software and electronic data system by pharmacy corporate bodies might assist the pharmacists in detecting and resolving DTRPs.

From the results, it was clear that vignettes with prescriptions generated more contact with the physician and $61-89 \%$ of the pharmacists made appropriate recommendations. In a related study in Sydney by Gisev et al. [14] among clients of community mental health teams, $81 \%$ of the recommendations made by pharmacists to resolve DTRPs were judged appropriate. This high level of appropriate recommendations is in keeping with part of our findings. Pharmacists recommendations of possible resolutions to DTRPs have varied acceptance rates among physicians [8]. Because of the design of this study, we did not evaluate the level of acceptance of the pharmacist recommendations since a SP model was used and one of the authors acted as "the pseudo-physician" to receive the pharmacists call on clarifications and suggestions based on the SP's vignette.

The national gender distribution of community pharmacists is in contrast with the global trend of female pharmacists been more predominant $[41,51,52]$. The ratio of male:female pharmacists in the country is 1.6:1. This is the same with the regional gender distribution of pharmacists. In our study male to female ratio is 1.4:1 which is almost similar to the national figure and gender distribution at the state level.

\section{Strengths and limitations of the study}

Since most DTRPs are self-reported and subjective with its attendant limitations of honesty of reporting and recall bias [15], the design of this study afforded an objective measure of community pharmacists practice of identifying and resolving DTRPs. The study is however not without some limitations. The simulated patient model may be prone to Hawthorne effect, but the possibility 
was reduced using three different SPs and vignettes. The pharmacists could not have altered their behaviour during the SPs' visits since they were unaware of the time of the visits. Only one pharmacist correctly suspected a SP visit. A limited number of SPs were used compared with the number of patients seen in the community pharmacies. However, the use of many SPs may also make the pharmacists suspicious and hence modify their behaviour. The three vignettes used do not represent the full remit of pharmacy practice and one visit per SP does not necessarily imply that the behaviour is always similar. Also, the number of community pharmacies involved in the study was small, but this was improved upon by the number of visits to the pharmacies. Furthermore, because the study was carried out in one state in Nigeria, it may not be representative of the practice of community pharmacists in other states in the country. Recall bias was also prevented by audiotaping the conversation between the pharmacists and the SPs.

\section{Conclusion}

The community pharmacists displayed a fair ability to detect and resolve drug therapy-related problems visà-vis identification of drug therapy-related problems, investigation of the causes and recommendations for resolution. The findings here are limited to the vignettes used. Further studies employing a wide array of vignettes may provide more information on the ability of community pharmacists to detect and resolve drug therapyrelated problems. Nonetheless, there is a need for the Pharmacists Council of Nigeria to include courses on the identification and resolution of drug therapy-related problems in Continuing Education Program for community pharmacists to enhance the practice.

\section{Abbreviations}

DTRPs: Drug therapy-related problems; SPs: Simulated patients; LGAs: Local government areas.

\section{Supplementary Information}

The online version contains supplementary material available at https://doi. org/10.1186/s12913-022-07535-z.

\section{Additional file 1.}

\section{Additional file 2.}

\section{Acknowledgements}

We thank the community pharmacies and superintendent pharmacists who participated in the study and the three simulated patients who assisted in data collection.

\section{Authors' contributions}

SJS conceived and designed the study, supervised data collection, analysed and interpreted the results, wrote, and reviewed the manuscript draft. LSD was involved in the study design, data collection, analysis and interpretation of results. LSD was involved in manuscript review. All authors read and approved the final manuscript.

\section{Funding}

This research received no specific grant from any funding agency in the public, commercial, or not-for-profit sectors.

\section{Availability of data and materials}

The datasets generated during and/or analysed during the current study are available from the corresponding author on reasonable request.

\section{Declarations}

\section{Ethics approval and consent to participate}

Ethics approval was obtained from the University of Ibadan and University College Hospital Ethics Review Committee with approval number UI/EC/19/0444.

The procedures used in this study adhered to the tenets of the Declaration of Helsinki [53]. Informed consent was sought from each superintendent pharmacist of the selected community pharmacies through a letter that informed them of the intention to conduct a questionnaire guided survey and impromptu SP visits, with the recording of the encounter, to evaluate pharmaceutical care practice. All the 40 superintendent pharmacists gave written informed consent.

\section{Consent for publication}

Not applicable.

\section{Competing interests}

The authors declare that they have no competing interests.

Received: 20 June 2021 Accepted: 24 January 2022

Published online: 16 February 2022

References

1. Cipolle RJ, Strand ML, Morley CP. The patient-centered approach to medication management services. In: the patient-centered approach to medication management services. 3rd ed. New York: McGraw-Hill International; 2012.

2. Repp KL, Hayes C, Woods TM, Allen KB, Kennedy K, Borkon MA. Drugrelated problems and hospital admissions in cardiac transplant recipients. Ann Pharmacother. 2012;46(10):1299-307.

3. van Mil F. Drug-related problems: a cornerstone for pharmaceutical care. J Malta Coll Pharm Pract. 2005;10:5-8.

4. van Mil JF, Westerlund LT, Hersberger KE, Schaefer MA. Drug-related problem classification systems. Ann Pharmacother. 2004;38(5):859-67.

5. Ayalew MB, Tegegn HG, Abdela OA. Drug related hospital admissions; a systematic review of the recent literatures. Bull Emerg Trauma. 2019;7(4):339-46.

6. Viktil KK, Blix HS. The impact of clinical pharmacists on drug-related problems and clinical outcomes. Basic Clin Pharmacol Toxicol. 2008;102(3):275-80.

7. Belayneh YM, Amberbir G, Agalu A. A prospective observational study of drug therapy-related problems in medical ward of a referral hospital in Northeast Ethiopia. BMC Health Serv Res. 2018;18(1):808.

8. Blix HS, Viktil KK, Moger TA, Reikvam A. Characteristics of drug-related problems discussed by hospital pharmacists in multidisciplinary teams. Pharm World Sci. 2006;28(3):152-8.

9. Adisa R, Osoba DO. Evaluation of drug therapy-related problems among outpatient hypertensive and Type-2-diabetic patients at a tertiary hospital, South-West Nigeria. Niger J Pharm Res. 2020;15(2):127-41.

10. Gudi SK, Kashyap A, Chhabra M, Rashid M, Tiwari KK. Impact of pharmacist-led home medicines review services on drug-related problems among the elderly population: a systematic review. Epidemiol Health. 2019;41:e201e9020.

11. Brady A, Curtis CE, Jalal Z. Screening tools used by clinical pharmacists to identify elderly patients at risk of drug-related problems on hospital admission: a systematic review. Pharm Basel Switz. 2020;8(2):64. https://doi.org/10. 3390/pharmacy8020064. 
12. Spinewine A, Dhillon S, Mallet L, Tulkens PM, Wilmotte L, Swine C. Implementation of ward-based clinical pharmacy services in Belgium--description of the impact on a geriatric unit. Ann Pharmacother. 2006;40(4):720-8.

13. Viktil KK, Blix HS, Moger TA, Reikvam A. Interview of patients by pharmacists contributes significantly to the identification of drug-related problems (DRPs). Pharmacoepidemiol Drug Saf. 2006;15(9):667-74.

14. Gisev N, Bell JS, O'Reilly CL, Rosen A, Chen TF. An expert panel assessment of comprehensive medication reviews for clients of community mental health teams. Soc Psychiatry Psychiatr Epidemiol. 2010;45(11):1071-9.

15. Ewan MA, Greene RJ. Evaluation of mental health care interventions made by three community pharmacists—a pilot study. Int J Pharm Pract. 2001;9(4):225-34.

16. Showande SJ, Adelakun AR. Management of uncomplicated gastric ulcer in community pharmacy: a pseudo-patient study. Int J Clin Pharm. 2019;41(6):1462-70.

17. Collins JC, Schneider CR, Faraj R, Wilson F, de Almeida Neto AC, Moles RJ. Management of common ailments requiring referral in the pharmacy: a mystery shopping intervention study. Int J Clin Pharm. 2017;39(4):697-703.

18. Watson MC, Norris P, Granas AG. A systematic review of the use of simulated patients and pharmacy practice research. Int J Pharm Pract. 2006;14(2):83-93.

19. Björnsdottir I, Granas AG, Bradley A, Norris P. A systematic review of the use of simulated patient methodology in pharmacy practice research from 2006 to 2016. Int J Pharm Pract. 2020;28(1):13-25.

20. Paravattil B, Kheir N, Yousif A. Utilization of simulated patients to assess diabetes and asthma counseling practices among community pharmacists in Qatar. Int J Clin Pharm. 2017;39(4):759-68.

21. Driesen A, Vandenplas Y. How do pharmacists manage acute diarrhoea in an 8-month-old baby? A simulated client study. Int J Pharm Pract 2009;17(4):215-20.

22. Showande SJ, Orok EN. Impact of pharmacists' training on oral anticoagulant counseling: a randomized controlled trial. Patient Educ Couns. 2021;104(5):1253-9.

23. Kennelty KA, Chewning B, Wise M, Kind A, Roberts T, Kreling D. Barriers and facilitators of medication reconciliation processes for recently discharged patients from community pharmacists' perspectives. Res Soc Adm Pharm. 2015;11(4):517-30.

24. Farris KB, Kirking DM. Beliefs of community pharmacists on prevention and correction of potential drug therapy-related problems. J Pharm Technol. 1996;12(5):223-30.

25. Ramalho-de Oliveira D, Shoemaker SJ, Ekstrand M, Alves MR. Preventing and resolving drug therapy-related problems by understanding patients' medication experiences. J Am Pharm Assoc. 2012;52(1):71-80.

26. Lynn MR. Determination and quantification of content validity. Nurs Res. 1986;35(6):382-5.

27. Adibe MO, Igboeli NU, Ukwe CV. Evaluation of drug therapy-related problems among renal patients receiving care in some tertiary hospitals in Nigeria. Trop J Pharm Res. 2017;16(3):697-704.

28. Soendergaard B, Kirkeby B, Dinsen C, Herborg H, Kjellberg J, Staehr P. Drugrelated problems in general practice: results from a development project in Denmark. Pharm World Sci. 2006;28(2):61-4.

29. Tefera GM, Zeleke AZ, Jima YM, Kebede TM. Drug therapy-related problems and the role of clinical pharmacist in surgery Ward: prospective observational and interventional study. Drug Healthc Patient Saf. 2020;12:71-83.

30. Van Lint JA, Sorge LA, Sorensen TD. Access to patients' health records for drug therapy-related problem determination by pharmacists. J Am Pharm Assoc. 2015;55(3):278-81.

31. Vinks THAM, de Koning FHP, de Lange TM, Egberts TCG. Identification of potential drug-related problems in the elderly: the role of the community pharmacist. Pharm World Sci. 2006;28(1):33-8.

32. Westberg SM, Derr SK, Weinhandl ED, Adam TJ, Brummel AR, Lahti J, et al. Drug therapy-related problems identified by pharmacists through comprehensive medication management following hospital discharge. J Pharm Technol. 2017;33(3):96-107.

33. Williams M, Peterson GM, Tenni PC, Bindoff IK, Curtain C, Hughes J, et al. Drug-related problems detected in Australian community pharmacies: the PROMISe trial. Ann Pharmacother. 2011;45(9):1067-76.

34. Hamid AA, Ghaleb M, Aljadhey H, Aslanpour Z. A systematic review of hospitalization resulting from medicine-related problems in adult patients. Br J Clin Pharmacol. 2014;78(2):202-17.
35. Ojeh VB, Naima N, Abah IO, Falang KD, Lucy O, London I, et al. Pattern of drug therapy-related problems and interventions in ambulatory patients receiving antiretroviral therapy in Nigeria. Pharm Pract. 2015;13(2):566.

36. Niriayo YL, Kumela K, Kassa TD, Angamo MT. Drug therapy-related problems and contributing factors in the management of heart failure patients in Jimma University specialized hospital, Southwest Ethiopia. PLoS One. 2018;13(10):e0206120

37. Williams M, Peterson GM, Tenni PC, Bindoff IK. A clinical knowledge measurement tool to assess the ability of community pharmacists to detect drug-related problems. Int J Pharm Pract. 2012;20(4):238-48.

38. University of Benin. Special PharmD Conversion Program. 2018. Benin City: University of Benin. Available from: http://www.unibenpharmd.net/. [cited 2021 Dec 29].

39. Why Nigerian varsities delay in starting PharmD degree —PCN registrar. Healthwise. 2020. Available from: https://healthwise.punchng.com/whynigerian-varsities-delay-in-starting-pharmd-degree-pcn-registrar/. [cited 2022 Jan 3]

40. Obayendo T. PSN officially receives pharm. D approval letter: Pharmanewsonline; Lagos, Nigeria: 2016. Available from: https://pharmanewsonline. com/psn-officially-receives-pharm-d-approval-letter/. [cited 2022 Jan 3].

41. Ekpenyong A, Udoh A, Kpokiri E, Bates I. An analysis of pharmacy workforce capacity in Nigeria. J Pharm Policy Pract. 2018;11(1):20.

42. Update from the Registry - May 01, 2021. Pharmacists Council of Nigeria. 2021. Available from: https://www.pcn.gov.ng/update-from-the-registrymay-01-2021/. [cited 2021 Dec 29].

43. Bissell P, Ward P, Noyce PR. Variation within community pharmacy. 1. Responding to requests for over-the-counter medicines. J Soc Adm Pharm. 1997;14(1):1-15.

44. Norris PT. Purchasing restricted medicines in New Zealand pharmacies: results from a "mystery shopper" study. Pharm World Sci PWS. 2002;24(4):149-53.

45. Watson MC, Bond CM, Grimshaw JM, Mollison J, Ludbrook A, Walker AE. Educational strategies to promote evidence-based community pharmacy practice: a cluster randomized controlled trial (RCT). Fam Pract. 2002;19(5):529-36.

46. Kravitz RL, Epstein RM, Feldman MD, Franz CE, Azari R, Wilkes MS, et al. Influence of patients' requests for direct-to-consumer advertised antidepressants: a randomized controlled trial. J Am Med Assoc. 2005;293(16):1995-2002.

47. Kelly KM, Shiau D-S, Jukkola PI, Miller ER, Mercadante AL, Quigley MM, et al. Effects of age and cortical infarction on EEG dynamic changes associated with spike wave discharges in F344 rats. Exp Neurol. 2011;232(1):15-21.

48. Banks J, Shaw A, Weiss MC. Walking a line between health care and sales: the role of the medicines counter assistant. Pharm J. 2005;274(7349):586-9.

49. Smith FJ, Salkind MR. Factors influencing the extent of the pharmacist's advisory role in greater London. Pharm J. 1990;244(Suppl):R4-7.

50. Strømme HK, Haugli A. Communication and interaction between customers and pharmacy personnel in two Norwegian pharmacies-an observational study. Int J Pharm Pract. 1996:4(4):209-13.

51. Bates I, John C, Bruno A, Fu P, Aliabadi S. An analysis of the global pharmacy workforce capacity. Hum Resour Health. 2016;14(1):1-7.

52. Bates I, John C, Seegobin P, Bruno A. An analysis of the global pharmacy workforce capacity trends from 2006 to 2012. Hum Resour Health. 2018;16(1):1-9.

53. World Medical Association. World medical association declaration of Helsinki ethical principles for medical research involving human subjects. Clin Rev Educ. 2013;310(20):2191-4.

\section{Publisher's Note}

Springer Nature remains neutral with regard to jurisdictional claims in published maps and institutional affiliations. 